Nodulation Studies

\title{
in the Model Legume Medicago truncatula: Advantages of Using the Constitutive EF1 $\alpha$ Promoter and Limitations in Detecting Fluorescent Reporter Proteins in Nodule Tissues
}

\author{
Marie-Christine Auriac and Antonius C. J. Timmers \\ Laboratory of Plant Microorganism Interactions, CNRS/INRA, UMR2594, 24 Chemin de borderouge, 31326 Castanet- \\ Tolosan, France
}

Submitted 5 January 2007. Accepted 20 March 2007.

\begin{abstract}
The Cauliflower mosaic virus $35 \mathrm{~S}$ promoter currently is being used in RNAi-based approaches for attenuating host gene expression during legume root nodule development and also for the expression of fluorescent reporters in nodule tissues. In this study, we have evaluated the expression of this promoter in the indeterminate nodules of the model plant Medicago truncatula. Our results clearly show that the $35 \mathrm{~S}$ promoter is inactive in both the nodule meristem and in bacteroid-containing cells of the nodules. On the other hand, the Arabidopsis thaliana EF1 $\alpha$ promoter was found to be strongly expressed both in the nodule meristem and in all nodule-invaded cells. Therefore, we conclude that the constitutive $E F 1 \alpha$ promoter is far superior for mRNAi or overexpression studies in nodule tissues compared with the commonly used $35 \mathrm{~S}$ promoter. In addition, our experiments have revealed that the intensity of fluorescent markers such as green fluorescent protein is severely attenuated within invaded cells in the nitrogen-fixation zone of the nodule, most likely by fluorescence quenching. This phenomenon may hinder the use of these tools for live-cell imaging in nodule tissue.
\end{abstract}

Additional keywords: Sinorhizobium meliloti.

A widely used model system for the study of nodulation is the interaction between the legume Medicago truncatula and the soil bacterium Sinorhizobium meliloti (Cook 1999). Freeliving bacteria penetrate into the plant root tissue by means of initial root hair infection and subsequent internalization through a tubular structure, the so-called infection thread. A new plant organ, the nodule, is formed at the site of infection in which the bacteria are released from infection threads and differentiate into nitrogen-fixing bacteroids classified as type 4 bacteroids (Vasse et al. 1990). M. truncatula nodules are of the

Corresponding author: C. J. Timmers; Telephone: +33 (0)5 612850 51; E-mail: ton.timmers@toulouse.inra.fr

This article is in the public domain and not copyrightable. It may be freely reprinted with customary crediting of the source. The American Phytopathological Society, 2007. indeterminate type which characteristically possess a persistent apical meristem (zone I), bordered by the infection zone (zone II), with the growing infection thread network at its distal part, and the liberation of bacteria into the plant cells in its proximal part, a narrow zone (interzone II-III) typified by an abundance of amyloplast, the symbiotic zone (zone III) where nitrogen fixation takes place, and, finally, the senescent zone (zone VI).

In spite of the wide use of the 35S Cauliflower mosaic virus (CaMV) promoter and autofluorescent proteins in nodulation studies with $M$. truncatula and $S$. meliloti (Complainville et al. 2003, Limpens et al. 2003, Monahan-Giovanelli et al. 2006), no detailed study of the activity of the $35 \mathrm{~S}$ promoter in $M$. truncatula and the behavior of autofluorescent proteins within these organisms has been carried out so far. However, for the correct interpretation of the results obtained in studies with these organisms, precise knowledge about their behavior is indispensable.

In general, the $35 \mathrm{~S}$ promoter is highly active in many cell types and, therefore, often described as constitutive; however, in a number of plant species, differential expression patterns have been observed. For example, in the widely used model plant, Arabidopsis thaliana, expression in leaves is roughly threefold higher than in roots. When using $\beta$-glucuronidase (GUS) as reporter, in general, strong staining occurs in all plant parts with the exception of the hypocotyl, which only stains slightly. Futhermore, in A. thaliana, the $35 \mathrm{~S}$ promoter often appeared very patchy (Holtorf et al. 1995). Moreover, the significance of studying in detail the expression pattern of the $35 \mathrm{~S}$ promoter in $M$. truncatula during the interaction with $S$. meliloti is underscored by previous reports about differential expression in nodules of Vicia hirsuta (Quandt et al. 1993), M. sativa (Samac et al. 2004), and actinorhizal nodules of Casuarina glauca and Allocasuarina verticillata (Obertello et al. 2005).

At the present time, fluorescent molecules are routine tools as markers of gene expression, protein localization and interaction with other proteins, and cellular dynamics (Chapman et al. 2005). The in vivo expression of fusions to fluorescent proteins generally is a first method of choice in such studies. A large number of fluorescent proteins has been identified and their fluorescence characteristics span the entire visible spectrum (Shaner et al. 2005), allowing multicolor experiments that 
combine the simultaneous expression of several fluorescent proteins within the same cell. On the other hand, their behavior under physiological conditions can differ significantly and the final detected signal may vary depending on the environment of the protein. For example, most fluorescent proteins are acid sensitive, which may give poor results in acidic compartments such as the plant cell vacuole (Shaner et al. 2005). Nonetheless, fluorescent proteins are used widely with success in plants (Brandizzi et al. 2002) and no specific problems with their use in plants cells have been reported to our knowledge thus far. However, during our studies on nodule organogenesis, we failed to observe intense fluorescence in the symbiotic zone of nodules of $M$. truncatula infected with $S$. meliloti which expresses green fluorescent protein (GFP). Therefore, we decided to study in detail the behavior of fluorescent molecules in living and fixed-nodule tissues, and we present our results here.

\section{RESULTS}

\section{Promoter activity in roots and nodules.}

The activity of the widely used CAMV $35 \mathrm{~S}$ promoter was studied in roots and nodules of $M$. truncatula by assaying the intensity of GFP fluorescence. Transformed roots were obtained by Agrobacterium rhizogenes-mediated gene transfer, and nodule development took place on roots of composite plants within an aeroponic culture system. Within roots, intense fluorescence was observed all along the root, with the highest intensity within the root tip containing the root cap and the meristematic region (Fig. 1A). Fluorescence appeared to be slightly lower in the elongation zone of the root compared with the intensity observed in the mature region of the root (results not shown). All tissues within the root were positive, with a slight increase in fluorescence intensity in the central cylinder (results not shown).

In nodules, the pattern of activity of the $35 \mathrm{~S}$ promoter appeared to be very different from the one observed in roots. Within the central regions of the nodule, no staining, indicative of promoter activity, was observed in zone I, the meristematic region of the nodule. Surprisingly, in zone II, the infection zone, and zone III, the nitrogen-fixing zone, of the nodule, fluorescence could be observed only in noninvaded cells (Fig. 1B). Moreover, fluorescence intensity was low in zone II compared with the intensity found in zone III. Both the nodule parenchyma and the vascular system were highly fluorescent. In contrast, GFP fluorescence was completely absent from invaded cells in both zone II and zone III.

In order to verify whether the observation of the absence of fluorescence is really indicative for an absence of promoter activity and not due to a specific property of GFP in invaded cells, promoter activity also was analyzed with GUS as reporter. In both roots (Fig. 1C) and nodules (Fig 1D), the patterns previously found with GFP were confirmed (i.e., strong promoter activity in root tips and complete absence of promoter activity in invaded cells of nodules).

From the above results, it is evident that a different promoter with a high constitutive activity in invaded cells of nodules is necessary for the expression of cellular markers, proteins, or siRNAs in order to study cellular processes and protein function during nodule development. We decided to test the promoter of elongation factor $1 \alpha$ of $A$. thaliana, $\mathrm{pA} 1$, which has been characterized as a strong constitutive promoter by the group of Bernard Lescure from our institute (Axelos et al. 1989). In roots of M. truncatula, the expression pattern appeared to be comparable with the one observed with the $35 \mathrm{~S}$ promoter. We observed an overall GUS staining along the root with strong staining visible within the meris- tematic region of the root (Fig. 1E). The root cap appeared to show a lower promoter activity. Due to the intense staining of meristematic cells, secondary root initials could be identified very early in their development (results not shown). In contrast to the pattern in roots, the pattern of pA1 activity in nodules differed markedly from the one of $35 \mathrm{~S}$. All internal tissues of nodules were found to show strong promoter activity with strong staining within the meristematic region and invaded cells within zone III. Strong staining also was observed within the nodule vascular system; however, staining was weaker within the nodule parenchyma. Noninvaded cells were only weakly stained, indicating that, in these cell types, the activity of pA1 is low or absent.

As with the $35 \mathrm{~S}$ promoter, we verified the expression pattern of pA1 with GFP as reporter to exclude any reporter-specific results. Again, the promoter activity pattern was confirmed both in roots (Fig. 1G) and nodules (Fig. 1H); however, unexpectedly, a low-fluorescence signal was apparent within nodule zone III, with almost no difference in intensity between invaded and noninvaded cells (Fig. 1H). Because promoter activity was clearly recognized by GUS staining (Fig. 1F), the low level of fluorescence within zone III doesn't seem to be indicative of a low level of activity of pA1 but is caused by a process post transcriptionally.

\section{Behavior of bacterially expressed fluorescent proteins in nodules.}

As a tool to study the behavior of introduced fluorescence within nodules, we inoculated $M$. truncatula with GFP-expressing $S$. meliloti strains. Freshly made sections of 3- to 4week-old nodules were observed directly by fluorescence microscopy. Bacteria were found to be brightly fluorescent and easily observable as reported previously from other studies (Cheng and Walker 1998; Gage et al. 1996; Stuurman et al. 2000). Strong GFP fluorescence was observed in zone II from both bacteria within infection threads and bacteroids liberated in plant cells (Fig. 2A to C). However, fluorescence dropped suddenly at the distal border of zone III, resulting in a sharp boundary between zone II and zone III (Fig. 2A, arrow). In contrast, no drop in fluorescence intensity was apparent from bacteria within infection threads. In both nodule zones, bacteria within infection threads fluoresced brightly (Fig. 2C, arrowheads). Similar results were obtained with rhizobia expressing cyan fluorescent protein, yellow fluorescent protein, or DsRed (Fig. 2D for DsRed). Furthermore, in thick nodule sections observed under epifluorescence, zone II appeared to consist of a distal part where fluorescence was restricted to the infection threads, and a proximal part where a more diffuse fluorescence was apparent from the plant cell's cytoplasm due to the liberation of bacteria from infection threads (Fig. 2D). The sudden drop in fluorescence coincided with the passage from zone II to zone III, as is evident from the comparison between Figure $2 \mathrm{D}$ and $\mathrm{E}$. This corresponds to the location of interzone II-III, a thin zone of a few cell layers typified by the abundant presence of amyloplasts. The same cells which showed a low fluorescence intensity when observed under excitation with green light (540 to $552 \mathrm{~nm}$ ), the excitation used for DsRed, were found to fluoresce relatively strongly, with maximum intensity in yellow, when excited with blue light (455 to $495 \mathrm{~nm}$ ), the excitation used for GFP (Fig. 2F). The sudden change in fluorescence intensity, both the decrease of introduced fluorescence and the increase in autofluorescence, correlates with the onset of nitrogen fixation, which is restricted to invaded cells of zone III. This implies that the change in physiology associated with the process of nitrogen fixation is causally related to the observed sharp modification of fluorescence intensity between nodule zones II and III. 
In order to test the possibility that such a sudden drop in fluorescence intensity is merely the result of a decrease in activity of the bacterial promoter which drives the expression of the fluorescent reporter, we verified the expression of a fusion between GFP and GUS under the control of pTrp, the promoter used for GFP expression in the above experiments. The pattern of fluorescence within nodules containing bacteria expressing this construct was identical to the pattern presented above from nodules containing bacteria expressing GFP only (results not shown). On the contrary, GUS activity
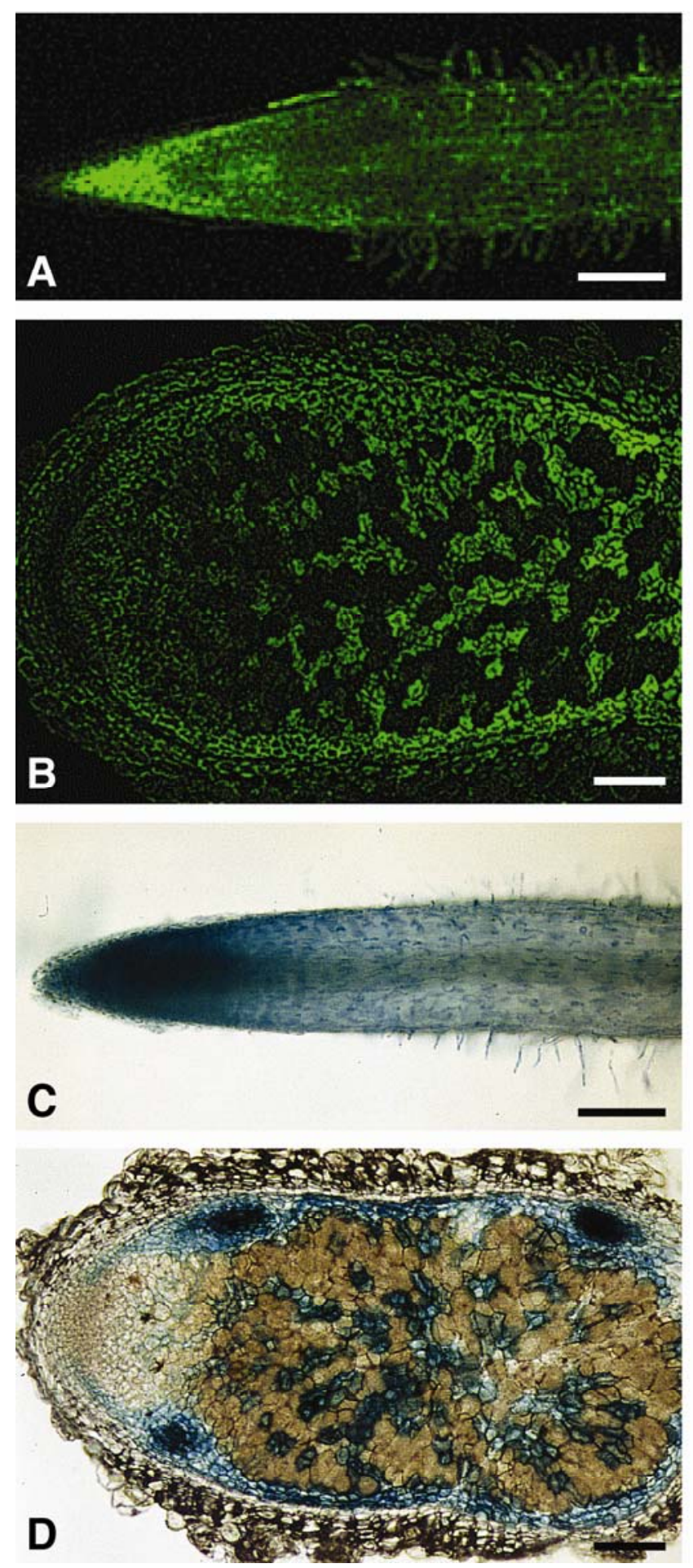
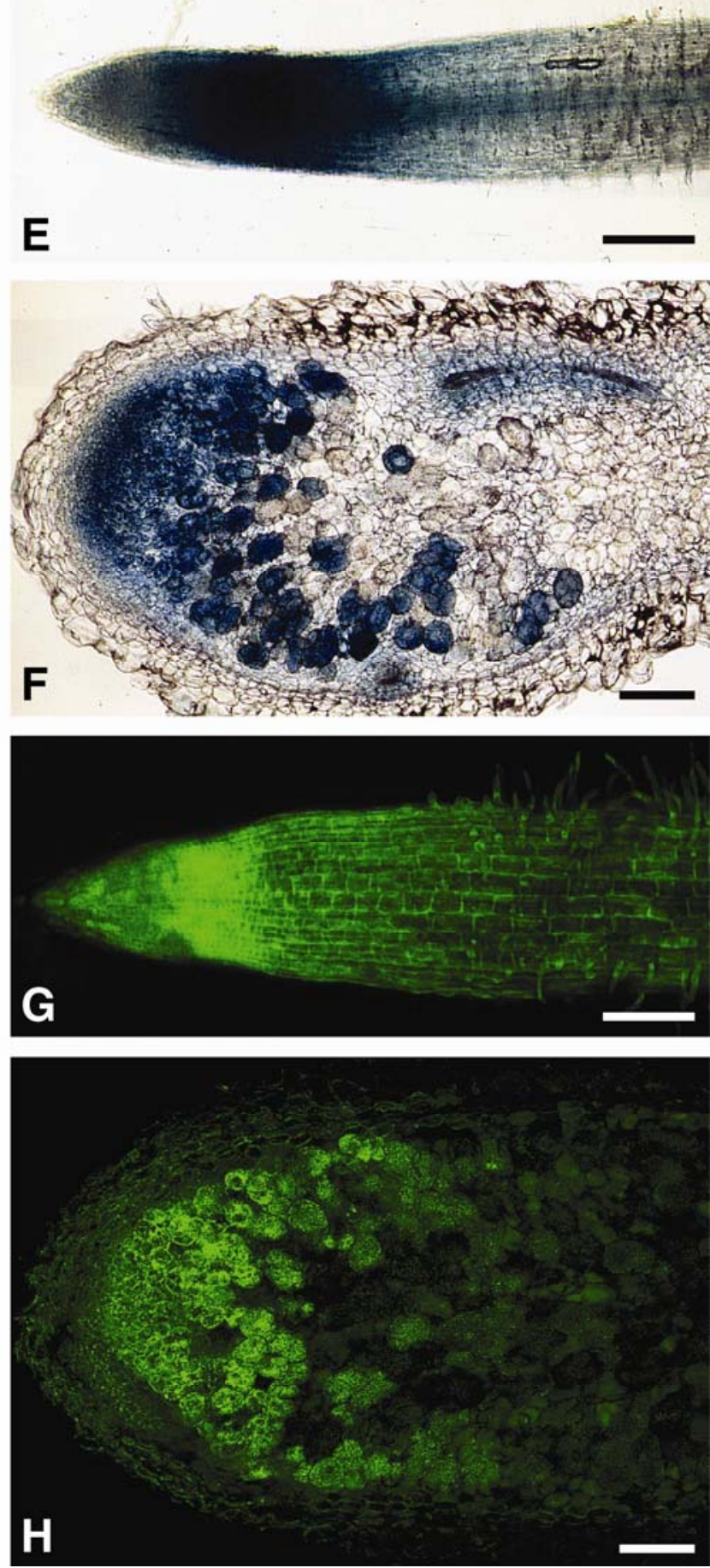

Fig. 1. A through D, 35S Cauliflower mosaic virus (CaMV) and $\mathbf{E}$ through $\mathbf{H}$, EF1 $\alpha$ promoter activity in roots and nodules of Medicago truncatula. A, Root tip region expressing green fluorescent protein (GFP) under control of the 35S CaMV promoter. B, Three-week-old nodule showing the expression restricted to noninvaded cells of GFP under control of the 35S CaMV promoter. C, GUS staining as a marker of 35S CaMV activity in a root tip. D, Three-week-old nodule with GUS expressed under control of the 35S CaMV promoter confirming the restriction of promoter activity to noninvaded cells. Also note the complete absence of staining within the nodule meristem. E, Root tip region expressing GUS under control of the EF1 $\alpha$ promoter. F, Three-week-old nodule showing the overall expression of GUS under the control of the EF1 $\alpha$ promoter. The absence of blue staining in some invaded cells is an experimental artefact. Cells which are cut during the preparation of the sections lose the cytosolic GUS and do not stain. G, Root tip region expressing GFP under control of the EF1 $\alpha$ promoter. $\mathbf{H}$, Three-week-old nodule with GFP expressed under control of the EF1 $\alpha$ promoter, confirming the intense staining of the meristem region and invaded cells. Noninvaded cells appear less intense. Bars $=100 \mu \mathrm{m}$. 
could be detected all along the nodule, in zone II and III, in both invaded cells and infection threads, clearly showing the constitutive nature of the promoter in $M$. truncatula nodules (results not shown).

After having confirmed that the promoter is active in nodule cells where GFP fluorescence is not observed, we investigated whether GFP was present in zone III cells containing bacteria expressing GFP by immunolocalization using GFPspecific antiserum and fluorescein isothiocyanate (FITC)conjugated secondary antibodies. As a control, we used cells containing wild-type rhizobia without GFP. We found that bacteroids expressing GFP in nodule zone III clearly showed a signal (Fig. 3A) whereas wild-type bacteroids showed only a weak autofluorescence (results not shown). From this, it was unequivocally demonstrated that although no GFP-specific fluorescence can be detected, GFP is expressed and formed in zone III of $M$. truncatula nodules.

The formation of the fluorophore of GFP requires the presence of oxygen (Tsien 1998). In contrast, nitrogenase, the key enzyme in biological nitrogen fixation, is very sensitive to oxygen and is irreversibly destroyed by oxygen. To ensure that nitrogen fixation take place, low oxygen pressure is maintained within zone III, by both the action of leghemoglobin and the presence of a cortical oxygen diffusion barrier. As a consequence of this low oxygen pressure, the formation of the fluorophore of GFP might be hindered. Thus, the sud-

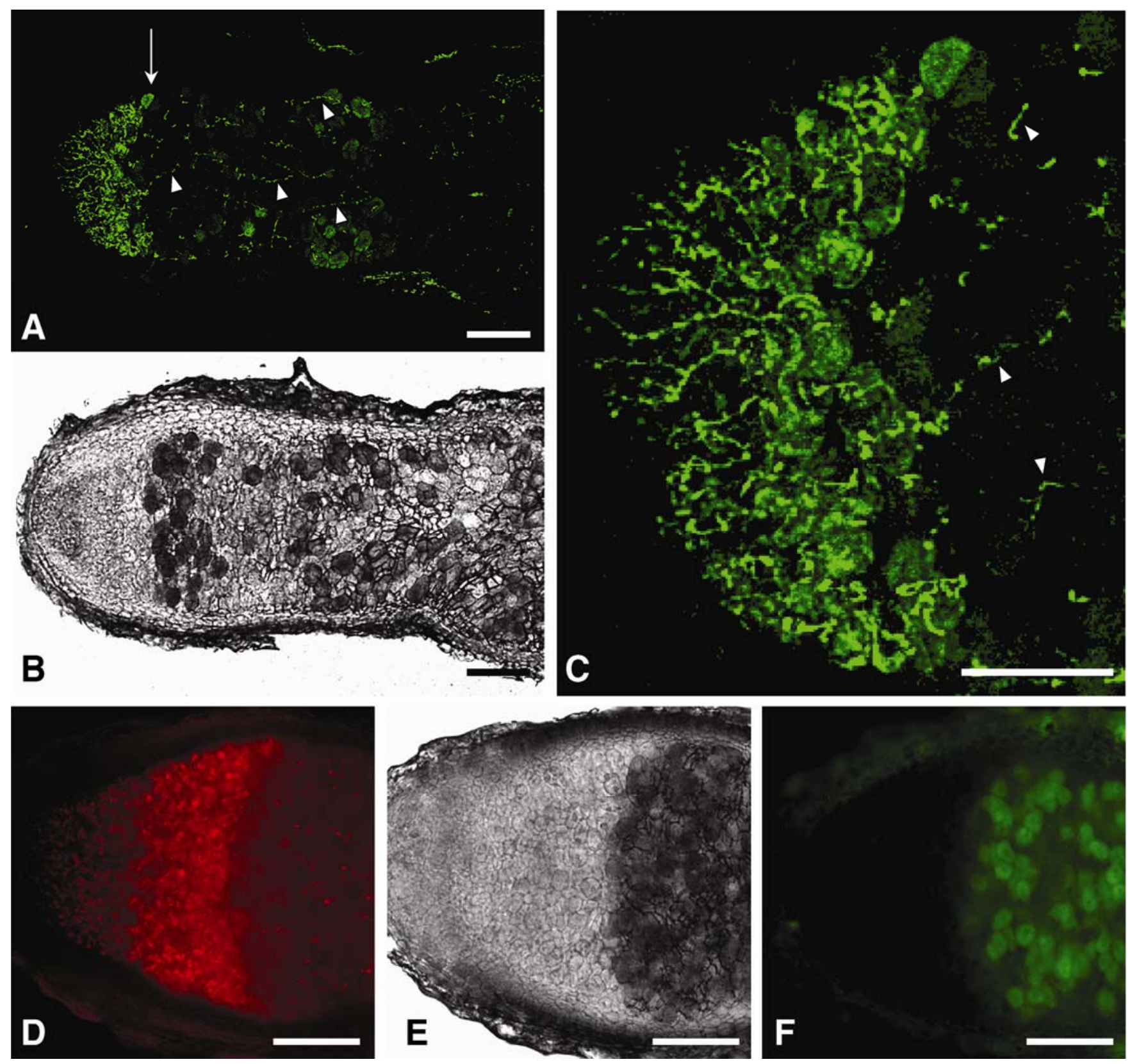

Fig. 2. Intensity of fluorescence of fluorescent proteins within bacteroids in nodules of Medicago truncatula. A, Three-week-old nodule infected with Sinorhizobium meliloti expressing green fluorescent protein (GFP). Note the strong fluorescence within zone II and the sudden drop in intensity at the border with zone III (arrow). Within zone III, only rhizobia within infection threads (arrowheads) fluoresce brightly. B, Bright-field image of A. C, Higher magnification of zone II and the distal part of zone III of the nodule shown in A. Arrowheads indicate the location of infection threads within zone III. D, Three-week-old nodule infected with S. meliloti expressing DsRed. As in A, a sudden drop in fluorescence marks the border between zone II and zone III. E, Bright-field image of D. F, The same nodule as in D and E observed with the conditions applied for the observation of GFP. Autofluorescence in this region of the spectrum is almost absent in zone II but relatively high in invaded cells of zone III. The image has been taken with a relatively long exposure time adapted to the level of autofluorescence. $\mathrm{A}$ and $\mathrm{B}$, bars $=200 \mu \mathrm{m} ; \mathrm{C}$ through $\mathrm{F}$, bars $=100 \mu \mathrm{m}$. 
den drop in fluorescence observed in nodules might be the result of the low oxygen pressure within nitrogen-fixing tissue. In order to verify this possibility, we first tried to recover GFP fluorescence by exposing nodule tissue to environmental oxygen. Hereto, we simply incubated nodule sections in water through which air was circulated for a period of $1 \mathrm{~h}$ to overnight. This never resulted in an increase in GFP fluorescence in nodule zone III (results not shown). Second, we replaced GFP within bacteroids with a GFP form that requires far less oxygen to mature. This is made possible by a simple point mutation within the amino acid sequence of GFP at position 64, just in front of the fluorophore, thereby replacing phenylalanine with cysteine. However, this also did not lead to any increase in fluorescence intensity in zone III (results not shown). From these results, we conclude that the absence of fluorescence within nodule zone III is not related to the low environmental oxygen pressure within nodules.

GFP has a typical three-dimensional (3D) structure consisting of a $\beta$-can with the fluorophore located at the center of the protein (Yang et al. 1996). GFP is only fluorescent if the $3 \mathrm{D}$ structure is correctly formed and if the protein is almost entirely intact. Only short deletions at either the $\mathrm{N}$ - or C-terminal part of GFP are tolerated ( $\mathrm{Li}$ et al. 1997). Because we showed above that GFP is present within zone III but nonfluorescent, an incorrect folding or partial degradation of the protein might be the cause of the low level of fluorescence in invaded nodule cells of zone III. If so, the fluorescence pattern should be typical for GFP and GFP-like proteins, and other fluorescent molecules with simpler 3D structures should not exhibit the same appearance. Thus, we tested the fluorescence pattern of two well-known fluorescent markers, SYTO9, a green fluorescent DNA marker, and acridine orange, a green fluorescent RNA marker. Nodule sections of wild-type nodules were incubated with either of these two dyes and observed by fluorescence microscopy using the appropriate filter set. Both markers appeared to fluoresce brightly in nodule zone II and, as with GFP, a sudden drop in fluorescence was detected at the border between zone II and III (Fig. 3B and $\mathrm{C}$ ). We consider it very unlikely that these three structurally different fluorescent molecules are prevented from fluorescing by the same mechanism; therefore, we conclude that the absence of fluorescence in nodule zone III is most likely caused by fluorescence quenching.

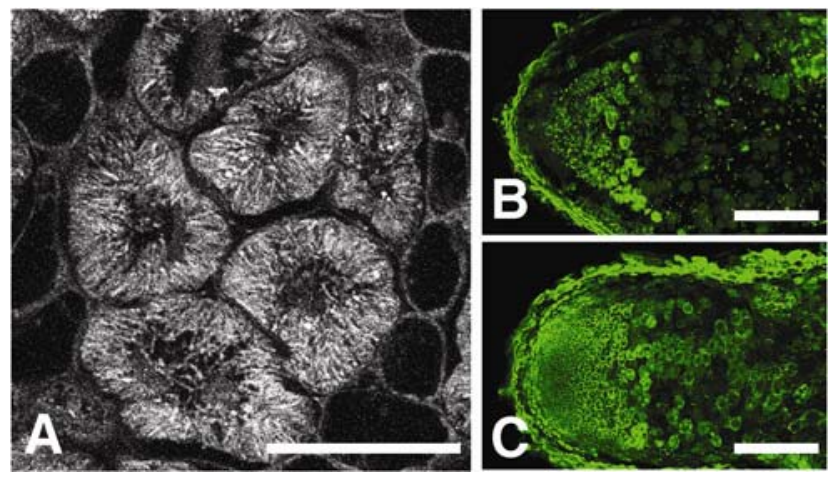

Fig. 3. Control experiments to explain the absence of fluorescence in nodule zone III. A, Antiserum directed against green fluorescent protein (GFP) clearly shows the presence of GFP in bacteroids in zone III, although only a very faint GFP-related fluorescence can be detected in this zone. B, Nodule treated with Syto9, a fluorescent DNA marker. Fluorescence intensity drops rapidly at the border between zone II and zone III. C, Nodule treated with the fluorescent RNA marker, acridine orange. Again, a drop in fluorescence intensity marks the border between nodule zone II and zone III. A, bars $=50 \mu \mathrm{m} ; \mathrm{B}$ and C, bars $=200 \mu \mathrm{m}$.

\section{DISCUSSION}

In the present study, we describe results which set hurdles to the use of the CaMV 35S promoter and autofluorescent proteins for the study of nodule organogenesis in M. truncatula. The $35 \mathrm{~S}$ promoter appears to be silenced in certain nodule tissues and autofluorescent proteins are quenched within the nitrogen fixation zone of nodules. These observations are discussed in relation to results published earlier and an alternative for the $35 \mathrm{~S}$ promoter is proposed.

The CaMV $35 \mathrm{~S}$ promoter appeared to be highly active in all cell types in roots of $M$. truncatula transformed with Agrobacterium rhizogenes. The highest GUS and GFP staining, indicative of promoter activity, was observed in the root-tip region and the central vascular bundle. Confocal microscopy of GFPexpressing roots showed that the root cap, especially, possesses high promoter activity in contrast to the meristem, where only faint staining was visible. A similar pattern of expression activity was observed in cotton (Sunilkumar et al. 2002), tobacco (Mitshuhara et al. 1996), and alfalfa (Samac et al. 2004). In contrast, in roots of soybean, expression levels were found to be relatively low, in particular in the procambium, phloem, and root cortex cells (Yang and Christou 1990). Thus, the $35 \mathrm{~S}$ promoter appears to be active in all root tissues of $M$. truncatula, although with different levels. Nonetheless, this differential expression should not hamper the use of the $35 \mathrm{~S}$ promoter in either localization, overexpression, or genesilencing experiments.

The situation is quite different for nodules. No promoter activity could be detected in the meristematic region, zone I, and only a very weak activity was present in the infection zone. A relatively strong activity was observed in the nitrogen-fixation zone and the nodule parenchyma. The strongest activity was reserved for the vascular tissue. In all symbiotic tissues, though, 35S promoter activity was restricted to the noninvaded cells. Absolutely no GUS staining or GFP fluorescence was observed in invaded cells, suggesting that rhizobial infection leads to silencing of the $35 \mathrm{~S}$ promoter. Comparable results have been published for nodules of V. hirsuta (Quandt et al. 1993) and M. sativa (Samac et al. 2004). Quandt and associates (1993) reported an absence of activity in the nodule meristem and infection zone and a strong response in the symbiotic zone of mature nodules, though without mentioning any difference between invaded and noninvaded cells. Samac and associates (2004) also reported the absence of activity in the nodule meristem (although in some of their stable transformants, the meristem was found to be positive for GUS activity) but low activity in the symbiotic zone of the nodule, again without noting any difference between invaded and noninvaded cells. In actinorhizal nodules of $C$. glauca, infected by the actinomycete Frankia, the $35 \mathrm{~S}$ promoter appeared to be most active in the vascular bundle, the phellogen, and strands of uninfected cells filled with polyphenols (Smouni et al. 2002). As in nodules of M. truncatula, invaded cells in C. glauca were devoid of any GUS enzymatic activity. Moreover, Obertello and associates (2005) reported that cortical nodule cells of Allocasuarina verticillata, also infected by Frankia, were devoid of GUS staining regardless of whether the cells were infected or not, and whatever the stage of nodule development. The same authors concluded that cis-elements from the CaMV domains interact with and respond to the symbiotic interaction, leading to silencing of expression. This silencing appears not to be restricted to nodulation. Also, during the infection with parasitic nematodes, a decrease in $35 \mathrm{~S}$ promoter activity was observed during maturation of the nematode feeding sites (Bertioli et al. 1999; Goddijn et al. 1993). Taking into consideration the data presented above, we conclude that the $35 \mathrm{~S} \mathrm{CaMV}$ promoter is 
unsuited for altering expression of genes involved in nodule organogenesis or functioning. A similar conclusion probably applies to plant-nematode interactions. To our knowledge, no study of the activity of the $35 \mathrm{~S}$ promoter during other plantmicroorganism interactions has been published; however, it appears highly desirable to test this activity for each specific interaction before using this promoter for localization studies or altering gene expression.

As an alternative to the $35 \mathrm{~S}$ promoter, we investigated the expression profile of the Arabidopsis EF1 $\alpha$ promoter, pA1 (Axelos et al. 1989). Under the same conditions used for the $35 \mathrm{~S}$ promoter (i.e., identical cloning vector and transformation procedures), the pA1 promoter showed high activity in all tissues of roots of $M$. truncatula, with an elevated level in meristematic regions. Within nodules, high activity was detected within the meristem, the infection zone, and the symbiotic zone as well as in vascular tissue. Remarkably, GUS staining and GFP fluorescence were low in noninvaded cells. Thus, the Arabidopsis pA1 promoter presents a good alternative for the $35 \mathrm{~S}$ promoter both for localization studies and for altering gene expression in nodules of M. truncatula. A second candidate is the Cassava vein mosaic virus promoter, which appears to be highly active in all nodule tissues of M. sativa (Samac et al. 2004). Thus far, no results with this promoter have been reported with $M$. truncatula. On the other hand, the differential activity of the $35 \mathrm{~S}$ promoter in internal tissues of $M$. truncatula nodules may be put into use as a means to separate invaded and noninvaded cells from the nodule symbiotic zone for use in transcriptomic and proteomic approaches by flow cytometry or laser microsurgery.

Autofluorescent proteins like GFP and its derivatives have been used successfully to follow rhizobia during early stages of nodulation in $M$. sativa (Gage 2002), and allowed a detailed study of the architecture of the developing infection thread network in the infection zone of nodules in $M$. truncatula (Monahan-Giovanelli et al. 2006). Fluorescently marked bacteroids in the symbiotic zone of the nodule have been shown clearly only for determinate type nodules on sirato (Stuurman et al. 2000). In addition, fluorescent marker proteins for cellular components like cytoskeletal elements have been used only during early stages of the symbiotic interaction (Sieberer et al. 2005), and no results of their use in the nodule symbiotic zone have been published thus far. In none of these studies was any specific problem related to the use of fluorescent proteins inside nodules reported. We observed, however, a strong difference in fluorescence intensity level between zone II and III in mature nodules of $M$. truncatula. Both rhizobia within infection threads and bacteroids liberated within the infected plant cells were intensely fluorescent within nodule zone II, but no GFP-related fluorescence could be detected within bacteroids in zone III. Rhizobia within infection threads, in contrast, were as fluorescent in zone III as they were in zone II. A similar drop in fluorescence intensity is observed equally when GFP is present within the plant cell protoplasm. Furthermore, this phenomenon is not specific to GFP, because the same pattern was observed with rhizobia expressing DsRed, a fluorescent protein with a number of characteristics different from GFP. For instance, DsRed is far less sensitive to changes in $\mathrm{pH}$ than GFP and is more photostable (Shaner et al. 2004). Moreover, other fluorescent molecules, such as the DNA stain SYTO9 and the RNA marker acridine orange, differed markedly in fluorescence intensity between zone II and zone III. This is noteworthy, because the DNA content of bacteroids increases significantly during their differentiation from the moment of their liberation until the stage of nitrogen-fixing bacteroid, the so-called type 4 bacteroids (Mergaert et al. 2006). On the other hand, the sudden drop is typical for invaded nodule cells. Noninvaded cells which expressed GFP under control of the $35 \mathrm{~S}$ promoter were intensely fluorescent in nodule zone III. Although not reported explicitly by Haynes and associates (2004), in nodules of M. truncatula stained with SYTO13, a decrease in fluorescence intensity was apparent when going from zone II toward zone III (Haynes et al. 2004). From these data, we conclude that invaded nodule cells represent an environment unfavorable to fluorescence due to fluorescence quenching. For the moment, we do not know which cellular component is responsible for the quenching, and additional studies are necessary to define the cause for the specific fluorescence quenching in the symbiotic zone of nodules.

\section{MATERIALS AND METHODS}

\section{Bacterial strains.}

All strains used in this study were grown on Luria-Bertani medium supplemented with appropriate selective antibiotics at $28^{\circ} \mathrm{C}$ (Sinorhizobium and Agrobacterium strains) or $37^{\circ} \mathrm{C}$ (Escherichia coli). Transformation of $S$. meliloti was done by triparental conjugation (David et al. 1988). Binary vectors were introduced into Agrobacterium rhizogenes by the freeze-thaw method, as described in Höfgen and Willmitzer (1988).

\section{Plasmid constructions.}

An overview of all plasmids used in this study can be found in Table 1. Plasmid constructs were made by using standard molecular biological techniques and E. coli strain DH5 $\alpha$ for plasmid multiplication.

For introduction of the point mutation F64C into GFP, the fragment containing the part of $s m G F P$ (U70495) from nucleotide 168 to 743 (end) was polymerase chain reaction (PCR)

Table 1. Plasmids used in this study

\begin{tabular}{|c|c|c|c|}
\hline Plasmid & Resistance $^{a}$ & Properties $^{b}$ & Reference \\
\hline 35SpBINmGFPER & $\mathrm{Km}$ & Marker for the ER & Haseloff et al. 1997 \\
\hline 35SpBIN-GUS (pLP100) & $\mathrm{Km}$ & Marker for $35 \mathrm{~S}$ activity & Szabados et al. 1995 \\
\hline A1pBIN-GUS & $\mathrm{Km}$ & Marker for A1 activity & Axelos et al. 1989 \\
\hline A1pBINmGFP5ER (F64C) & $\mathrm{Km}$ & Marker for the ER & This study \\
\hline pRJG37 & $\mathrm{Km}$ & NLS-GFP-GUS fusion & Grebenok et al. 1997 \\
\hline pTB93F & Tet & GFP under control of $p$ Trp & Gage et al. 1996 \\
\hline pDG77 & Tet & DsRed under control of pTrp & Bringhurst et al. 2001 \\
\hline pME6010 & Tet & Stabilization fragment & Heeb et al. 2000 \\
\hline pMEpTrpGFP & Tet & Stable GFP expression & This study \\
\hline pMEpTrpGFP(F64C) & Tet & Modified GFP & This study \\
\hline pMEpTrpGFPGUS & Tet & Bacterial GFPGUS expression & This study \\
\hline pMP4656 & Tet & Bacterial cyan fluorescent protein expression & Stuurman et al. 2000 \\
\hline pMP4639 & Tet & Bacterial yellow fluorescent protein expression & Stuurman et al. 2000 \\
\hline
\end{tabular}

\footnotetext{
${ }^{\mathrm{a}} \mathrm{Km}=$ kanamycin and Tet $=$ tetracycline

${ }^{\mathrm{b}} \mathrm{ER}=$ endoplasmic reticulum, NLS-GFP-GUS = nuclear localization signal-green fluorescent protein- $\beta$-glucuronidase .
} 
amplified using pUC-smRS-GFP (Davis and Vierstra 1998) as template with the primers CCGTGGCCAACACTTGTCACTA CTTGCACTTATGGTG and GAATTCCTGCAGGAGCTCTT ATTTGTATAGTTC, and cloned into pUC-smRS-GFP using BalI and SacI.

In order to put the expression of mGFP5ER under the control of the promoter of elongation factor $1 \alpha$, named pA1, two restriction sites, $B s p \mathrm{HI}$ and $P s t \mathrm{I}$, were created $5^{\prime}$ and $3^{\prime}$, respectively, around the mGFP5ER part of 35SpBINmGFP5ER by PCR. The obtained fragment was cloned into pUC-A1 opened with NcoI and PstI. The F64C mutation was introduced by cloning the NdeI-BalI fragment of F64C smRS-GFP into mGFP5-ER. The complete expression cassettes pA1-mGFP5ER-termA1 and pA1-mGFP5(F64C)-ER-termA1 were cloned into pBIN using KpnI and HindIII.

For bacterial expression of GFP, the complete expression cassette of pTB93F (Gage et al. 1996) with GFP expression under control of the constitutive promoter pTrp was cloned into the stable replicon pME6010 (Heeb et al. 2000). The F64C form of GFP was obtained by cloning the NcoI-NdeI fragment containing the N-terminal part of smGFP with the point mutation F64C into pTB93F. For simultaneous expression of GFP and GUS, the fragment containing a fusion between GFP and GUS from pRJG37 (Grebenok et al. 1997) was cloned behind pTrp in pTB93F using NcoI and XhoI. Both constructs, pTrp-GFP(F64C) and pTrp-GFPGUS, subsequently were cloned into pME6010 to guarantee stability within plant tissue without antibiotic selection.

\section{Plant material and root transformation.}

Seeds of M. truncatula cv. Jemalong were surface sterilized, germinated, and grown in test tubes on nitrogen-free agar slants (Ardourel et al. 1994) or aeroponically as described by Journet and associates (2001). Transformed roots were obtained by Agrobacterium rhizogenes-mediated gene transfer using the method described by Boisson-Dernier and associates (2001).

Plants were flood inoculated with exponentially grown bacterial cultures diluted in water to $\approx 10^{6}$ bacteria $/ \mathrm{ml}$. Nodules were harvested between 2 and 4 weeks after inoculation.

\section{Microscopy.}

For the observation of fluorescence within nodules, sections of $80 \mu \mathrm{m}$ either were prepared from fresh material with an H1200 microcut (Bio-Rad Laboratories, Watford, U.K.), mounted on slides in water, and observed directly with a straight microscope, or cut in two longitudinally with a razor blade, put with the cut face down on a cover slip, and observed with an inverted microscope. Observations and image registrations were made using a Zeiss Axiophot 2 (Carl Zeiss, Oberkochen, Germany) equipped with a Micromax 1300Y-HS CCD camera controlled by Metaview (Roper Scientific, Tucson, AZ, U.S.A.) or using the Leica TCS confocal system.

GUS activity was localized in nodule sections with the histochemical substrate 5-bromo-4-chloro-3-indolyl- $\beta$-D-glucuronide, cyclohexylammonium salt (Biosynth, Staad, Switzerland) and the protocol described by Journet and associates (1994). Images were taken with a Leica DC200 installed on a Zeiss Axiophot microscope.

\section{Immunolocalization of GFP.}

For immunolocalization, 3-week-old nodules containing rhizobia expressing GFP were fixed in a solution of $2 \%$ paraformaldehyde and $0.5 \%$ glutaraldehyde in phosphate-buffered saline (PBS) and embedded in PEG-stearate (Vitha et al. 1997). Labeling was done by subsequent incubation of section with anti-GFP (A6422; Molecular Probes, Eugene, OR, U.S.A.) diluted 200× and GAR/IgG (Fc)-FITC (Nordic) diluted
$100 \times$. Autofluorescence was quenched by incubation in a solution of $0.5 \%$ Evans blue in PBS.

\section{ACKNOWLEDGMENTS}

We gratefully acknowledge the generous gift of plasmids from $\mathrm{J}$. Haseloff, D. Galbraith, D. Gage, and N. Stuurman. We thank D. Barker for helpful advice for preparation of the manuscript.

\section{LITERATURE CITED}

Ardourel, M., Demont, N., Debellé, F., Maillet, F., de Billy, F., Promé, J. C., Dénarié, J., and Truchet, G. 1994. Rhizobium meliloti lipooligosaccharide nodulation factors: Different structural requirements for bacterial entry into target root hair cells and induction of plant symbiotic developmental responses. Plant Cell 6:1357-1374.

Axelos, M., Bardet, C., Liboz, T., Le Van Thai, A., Curie, C., and Lescure, B. 1989.. The gene family encoding the Arabidopsis thaliana translation elongation factor EF-1 alpha: Molecular cloning, characterization and expression. Mol. Gen. Genet. 219:106-112.

Bertioli, D. J., Smoker, M., and Burrows, R. 1999. Nematode-responsive activity of the Cauliflower mosaic virus $35 \mathrm{~S}$ promoter and its subdomains. Mol. Plant-Microbe Interact. 12:189-196.

Boisson-Dernier A, Chabaud M, Garcia F, Bécard G, Rosenberg C, and Barker D. G. 2001. Agrobacterium rhizogenes-transformed roots of Medicago truncatula for the study of nitrogen-fixing and endomycorrhizal symbiotic associations. Mol. Plant-Microbe Interact. 14:695700 .

Brandizzi, F., Fricker, M., and Hawes, C. 2002. A greener world: The revolution in plant bioimaging. Nat. Rev. Mol. Cell Biol. 3:520-530.

Bringhurst, R. M., Cardon, Z. G., and Gage, D. J. 2001. Galactosides in the rhizosphere: Utilization by Sinorhizobium meliloti and development of a biosensor. Proc. Natl. Acad. Sci. U.S.A. 98:4540-4545.

Chapman, S., Oparka, K. J., and Roberts, A. G. 2005. New tools for in vivo fluorescence tagging. Curr. Opin. Plant Biol. 8:565-573.

Cheng, H. P., and Walker, G. C. 1998. Succinoglycan is required for formation and elongation of infection threads during nodulation of alfalfa by Rhizobium meliloti. J. Bacteriol. 180:5183-5191.

Complainville, A., Brocard, L., Roberts, I., Dax, E., Sever, N., Sauer, N., Kondorosi, A., Wolf, S., Oparka, K., and Crespi, M. 2003. Nodule initiation involves the creation of a new symplastic field in specific root cells of Medicago species. Plant Cell 15:2778-2791.

Cook, D. R. 1999. Medicago truncatula-A model in the making! Curr. Opin. Plant Biol. 2:301-304.

David, M., Daveran, M. L., Batut, J., Dedieu, A., Domergue, O., Ghai, J., Hertig, C., Boistard, P., and Kahn, D. 1988. Cascade regulation of nif gene expression in Rhizobium meliloti. Cell 54:671-683.

Davis, S. J., and Vierstra, R. D. 1998. Soluble, highly fluorescent variants of green fluorescent protein (GFP) for use in higher plants. Plant Mol. Biol. 36:521-528.

Gage, D. F. 2002. Analysis of infection thread development using Gfpand DsRed-expressing Sinorhizobium meliloti. J. Bacteriol. 184:70427046.

Gage, D. J., Bobo, T., and Long, S. R. 1996. Use of green fluorescent protein to visualize the early events of symbiosis between Rhizobium meliloti and alfalfa (Medicago sativa). J. Bacteriol. 178:7159-7166.

Goddijn, O. J. M., Lindsey, K., van der Lee, F. M., Klap, J. C., and Sijmons, P. C. 1993. Differential gene expression in nematode-induced feeding structures of transgenic plants harbouring promoter-gusA fusion constructs. Plant J. 4:863-873.

Grebenok, R. J., Pierson, E., Lambert, G. M., Gong, F.-C., Afonso, C. L., Haldeman-Cahill, R., Carrington, J. C., and Galbraith, D. W. 1997. Green-fluorescent protein fusions for efficient characterization of nuclear targeting. Plant J. 11:573-586.

Haseloff, J., Siemering, K. R., Prasher, D. C., and Hodge, S. 1997. Removal of a cryptic intron and subcellular localisation of green fluorescent protein are required to mark transgenic Arabidopsis plants brightly. Proc. Natl. Acad. Sci. U.S.A. 94:2122-2127.

Haynes, J. G., Czymmek, K. J., Carlson, C. A., Veereshlingam, H., Dichstein, R., and Sherrier, D. J. 2004. Rapid analysis of legume root nodule development using confocal microscopy. New Phytol. 163:661668.

Heeb, S., Itoh, Y., Nishijyo, T., Schnider, U., Keel, C., Wade, J., Walsh, U., O'Gara, F., and Haas, D. 2000. Small, stable shuttle vectors based on the minimal pVS1 replicon for use in gram-negative plant-associated bacteria. Mol. Plant-Microbe Interact. 13:232-237.

Höfgen, R., and Willmitzer, L. 1998. Storage of competent cells for Agrobacterium transformation. Nucleic Acids Res. 16:9877. 
Holtorf, S., Appel, K., and Bohlmann, H. 1995. Comparison of different constitutive and inducible promotors for the overexpression of transgenes in Arabidopsis thaliana. Plant Mol. Biol. 29:637-646.

Journet, E.-P., Pichon, M., Dedieu, A., De Billy, F., Truchet, G., and Barker, D. G. 1994. Rhizobium meliloti Nod factors elicit cell-specific transcription of the ENOD12 gene in transgenic alfalfa. Plant J. 6:241-249.

Journet, E.-P., El-Gachtouli, N., Vernoud, V., De Billy, F., Pichon, M., Dedieu, A., Arnould, C., Morandi, D., Barker, D. G., and GianinazziPearson, V. 2001. Medicago truncatula ENOD11: A novel RPRP-encoding early nodulin gene expressed during mycorrhization in arbuscule-containing cells. Mol. Plant-Microbe Interact. 14:737-748.

Li, X., Zhang, G., Ngo, N., Zhao, X., Kain, S. R., and Huang, C.-C. 1997. Deletions of the Aequorea victoria green fluorescent protein define the minimal domain required for fluorescence. J. Biol. Chem. 272:2854528549.

Limpens, E., Franken, C., Smit, P., Willemse, J., Bisseling, T., and Geurts, R. 2003. LysM domain receptor kinases regulating rhizobial Nod factor-induced infection. Science 302:630-633.

Mergaert, P., Uchiumi, T., Alunni, B., Evanno, G., Cheron, A., Catrice, O., Mausset, A.-E., Barloy-Hubler, F., Galibert, F., Kondorosi, A., and Kondorosi, E. 2006. Eukaryotic control on bacterial cell cycle and differentiation in the Rhizobium-legume symbiosis. Proc. Natl. Acad. Sci. 103:5230-5235.

Mitshuhara, I., Ugaki, M., Hirochika, H., Ohshima, M., Murakami, T., Gotoh, Y., Katayose, Y., Nakamura, S., Honkura, R., Nishimiya, S., Ueno, K., Mochizuki, A., Tanimoto, H., Tsugawa, H., Otsuki, Y., and Ohashi, Y. 1996. Efficient promoter cassettes for enhanced expression of foreign genes in dicotyledonous and monocotyledonous plants. Plant Cell Physiol. 37:49-59.

Monahan-Giovanelli, H., Pinedo, C. A., and Gage, D. J. 2006. Architecture of infection thread networks in developing root nodules induced by the symbiotic bacterium Sinorhizobium meliloti on Medicago truncatula. Plant Physiol. 140:661-670.

Obertello, M. Santi, C., Sy, M.-O., Laplaze, L., Auguy, F., Bogusz, D., and Franche, C. 2005. Comparison of four constitutive promoters for the expression of transgenes in the tropical nitrogen-fixing tree Allocasuarina verticillata. Plant Cell Rep. 24:540-548.

Quandt, H.-J., Pühler, A., and Broer, I. 1993. Transgenic root nodules of Vicia hirsuta: A fast and efficient system for the study of gene expression in indeterminate-type nodules. Mol. Plant-Microbe Interact. 6:699-706.

Samac, D. A., Tesfaye, M., Dornbusch, M., Saruul, P., and Temple, S. J. 2004. A comparison of constitutive promoters for expression of transgenes in alfalfa (Medicago sativa). Transgenic. Res. 13:349-361.
Shaner, N. C., Campbell, R. E., Steinbach, P. A., Giepmans, B. N. G., Palmer, A. E., and Tsien, R. Y. 2004. Improved monomeric red, orange and yellow fluorescent proteins derived from Discosoma sp. red fluorescent protein. Nat. Biotechnol. 22:1567-1572.

Shaner, N. C., Steinbach, P. A., and Tsien, R. Y. 2005. A guide to choosing fluorescent proteins. Nat. Methods 2:905-909.

Sieberer, B. J., Timmers, A. C. J., and Emons, A. M. C. 2005. Nod factors alter the microtubule cytoskeleton in Medicago truncatula root hairs to allow root hair orientation. Mol. Plant-Microbe. Interact. 18:11951204.

Smouni, A., Laplaze, L., Bogusz, D., Auguy, F., Duhoux, E., and Franche, C. 2002. The $35 \mathrm{~S}$ promoter is not constitutively expressed in the transgenic tropical actinorhizal tree, Casuarina glauca. Funct. Plant Biol. 29:649-656.

Stuurman, N., Pacios Bras, C., Schlaman, H. R. M., Wijfjes, A. H. M., Bloemberg, G., and Spaink, H. P. 2000. Use of green fluorescent protein color variants expressed on stable broad-host-range vectors to visualize rhizobia interacting with plants. Mol. Plant-Microbe Interact. 13:1163-1169.

Sunilkumar, G., Mohr, L., Lopata-Finch, E., Emani, C., and Rathore, K. S. 2002. Developmental and tissue-specific expression of CaMV 35S promoter in cotton as revealed by GFP. Plant Mol. Biol. 50:463-474.

Szabados, L., Charrier, B., Kondorosi, A., De Bruijn, F. J., and Ratet, P. 1995. New plant promoter and enhancer testing vectors. Mol. Breed. 1:419-423.

Tsien, R. Y. 1998. The green fluorescent protein. Annu. Rev. Biochem. 67:509-544.

Vasse, J., De Billy, F., Camut, S., and Truchet, G. 1990. Correlation between ultrastructural differentiation of bacteroids and nitrogen fixation. J. Bacteriol. 172:4295-4306.

Vitha, S., Baluska, F., Mews, M., and Volkmann, D. 1997. Immunofluorescence detection of F-actin on low melting point wax sections from plant tissues. J. Histochem. Cytochem. 45:89-95.

Yang, F., Moss, L. G., and Phillips, G. N., Jr. 1996. The molecular structure of green fluorescent protein. Nat. Biotechnol. 14:1246-1251.

Yang, N.-S., and Christou, P. 1990. Cell type specific expression of a CaMV 35S promoter in transgenic tobacco. Plant Physiol. 90:1570-1576.

\section{AUTHOR-RECOMMENDED INTERNET RESOURCES}

Medicago truncatula website: www.medicago.org/

Free patents online: www.freepatentsonline.com/6414119.html 